\title{
Changing the Departmental Learning Culture to Enable Student-Centred Learning in Large Classes
}

\author{
Christel Troskie-de Bruin1 \\ Ruth M. Albertyn ${ }^{1}$ \\ Pauline Machika² \\ ${ }^{1}$ Centre for Higher and Adult Education, Stellenbosch University, South Africa \\ Email: asev@icon.co.za; rma@sun.ac.za \\ ${ }^{2}$ Academic Development and Support Centre, University of Johannesburg, South Africa \\ Email: paulinema@vut.ac.za
}

\section{Doi:10.5901/mjss.2014.v5n8p386}

\begin{abstract}
The fast changing workplace requires lifelong learners that can adapt and function effectively in a variety of circumstances. To equip students with the necessary knowledge and skills to be marketable and survive in the workplace is not easy, especially in the context of very large classes. In this mixed method study current practices and challenges related to teaching, learning and assessment were investigated at a South African university with classes of up to 800 students. Only the qualitative component of the study, which involved in-depth interviews with lecturers of these classes, is used for this article. We found that transfer of knowledge by lecturing and electronic assessments by means of multiple-choice questions (MCQs) were the dominant practices in these classes. Individual efforts by lecturers to use student-centred methods were met with resistance by both colleagues and students. We argue that this situation will not change unless the departmental learning culture changes to incorporate student-centred teaching, learning and assessment as classroom practice. Some examples are presented of viable ways to use peer- and self-assessment in these large classes which could be adopted as standard departmental teaching and learning practice.
\end{abstract}

Keywords: Large classes, formative assessment, departmental learning culture, student-centred teaching and learning, higher education

\section{Introduction}

Contradictory demands cloud lecturers' view of their task in the South African higher education environment. The demand for quality and accountability (CHE 2008; Metz 2010; Connor \& Rabovsky 2011) together with the demand to develop students' lifelong learning skills (DHET 2007; CHE 2013) placed disempowering pressure on lecturers of large classes. Accountability implies measuring student performance (Cheng 2012), while promoting lifelong learning requires the development of skills that are difficult to measure, especially in the large class context.

The emphasis on throughput rates and accountability (DoE 2001) forces higher education institutions (HEIs) into a mode of teaching and learning, which can be measured (Liu 2011). It encourages objective testing of the mastery of subject content. Multiple choice questions (MCQs) has been considered to be an effective method to test content knowledge of large numbers of students since after World War I and was the preferred method of assessment promoted by the Carnegie Foundation for several decades (Shavelson 2007). Assessing the mastery of content represents a view of education that is teacher-centred, for it focuses on knowledge transfer and rewards the amount of knowledge that can be obtained and retained by students (Yuen \& Hau 2006; Elen et al. 2007). With this approach to education, skills that are necessary for lifelong learning like critical thinking, reasoning, decision-making, inter-personal communication (Candy 2000) and so forth are not specifically developed or assessed.

To develop a wide range of student skills, the South African Qualification Authority (SAQA) has instituted the critical cross-fields outcomes for higher education (DoE 1997). These outcomes, now referred to as graduate attributes (CHE 2013) are based on lifelong learning principles similar to those put forth by Candy (1991) and imply having an interest in continuous learning; a holistic, integrated view of information; the use of a variety of learning skills, the development of self-managing and self-monitoring skills; developing information literacy, which includes the use of 
technology, and the development of critical thinking, reasoning and decision-making skills. To develop these skills, which can equip graduates to cope in a fast developing and ever-changing workplace (Naidoo \& Searle 1997; Schapper \& Mayson 2004), a student-centred approach to teaching, learning and assessment is necessary (Switzer 2004). However teacher- and student-centred teaching, learning and assessment methods are necessary in large classes (Moulding 2010).

There has been an escalation in the numbers of students in university classes worldwide (Papo 2001) and at SA universities (Naidoo \& Searle 1997). To cope with the large numbers of students in classes, the general trend, as indicated in international literature, is to use traditional lecturing as teaching method (Mulryan-Kyne 2010). Students are expected to passively absorb information while taking notes of the knowledge transferred in class (Moulding 2010). Electronic assessment by means of multiple-choice questions (MCQS) seems to be the practical assessment method and is thus often used (Switzer 2004). Although it is probably the easiest way to cope with a large number of students simultaneously, there are several disadvantages to the lecturing and MCQs as the only approach to teaching, learning and assessment.

De Zilwa (2007) warns that to survive, academic units should constantly monitor their external environment and adapt accordingly. Large classes are currently a direct consequence of SA HEls external environment, but the desired adaptation does not seem to take place. Since the 1990s, several authors (Gibbs 1992; Biggs 1999; McKeachie 1999; Papo 2001; Nicol \& Boyle 2003; Switzer 2004; Mompo \& Redoli 2010) have suggested alternative teaching and assessment methods to engage students in large classes and to develop higher order thinking skills. However, the numbers and diversity in large classes in the SA HE context, make the use of some of these proposed methods almost impossible. Therefore lecturers are bound to revert to what is do-able in a large class, namely lecturing and the use of MCQs for assessment (Paxton 2000). These practices will not change automatically.

To change the reliance on teacher-centred methods in large classes and incorporate the use of student-centred methods, we propose formative assessment as a strategy to engage students and to development lifelong learning skills. To be practical in large classes, it should not be used for grading but for developmental purposes only. However, unless there is a uniformly accepted departmental learning culture that fosters the inclusion of student-centred teaching, learning and assessment methods in large classes, the practice of using mainly teacher-centred methods like lecturing and MCQs will prevail. An academic department's learning culture influences both lecturer and student performance, because the interpretation of generic attributes that should be taught is influenced by the disciplinary culture in which they are taught (Jones 2009). The reason for this is because in higher education the values, beliefs and norms related to teaching, learning and assessment that are held by those involved in a specific academic department, determine what practices and methods are considered to be appropriate, and what kinds of staff and student performance earn quality rating.

The meaning of the term 'departmental learning culture' is interpreted in this article as the shared perceptions of departmental work practices (Van den Berg \& Wilderom 2004) that reflect aspects of the psychological environment of the department. These aspects, as described in the early organisational culture literature (Robbins 1996) are the core values, beliefs and norms held by members of a specific organisation. In the context of an academic department, the learning culture will thus refer to the values, beliefs and norms related to teaching, learning and assessment that are held by departmental staff and students. Very little information could be found in the literature about the role of the learning culture of a department in teaching, learning and assessment practices specifically in the large class context. The aim of this article is to illustrate how a departmental learning culture that fosters student-centred formative assessment can influence classroom practice and to indicate why the development of such a departmental culture is not only necessary, but also viable.

In a recent study that investigated how large classes are managed at a South African University, we found that the dominant current practice in large classes is still to use lecturing and MCQs, but there were clear indications that lecturers are willing to employ different methods of teaching and assessment, provided that they could achieve the desired learning outcomes through these methods. In the following section, literature related to learning culture in the HE context as well as self- and peer-assessment as student-centred formative assessment methods are discussed. Findings related to current classroom practices in large classes and challenges experienced by lecturers in these classes are presented. The article concludes with suggestions of how a departmental learning culture that fosters student-centred formative assessment can reduce or overcome some of these challenges.

\section{Literature Review}

The literature deals with learning culture, formative assessment in large classes and student-centred formative assessment. 


\subsection{Learning culture}

Since the late $20^{\text {th }}$ century, business principles have been applied to the management of higher education institutions (HEIs) (Guzman \& Trivelato 2010). After the publication of Senge's (1990) seminal work about the learning organisation, the emphasis on organisational culture as a learning culture (Holyoke et al. 2012) found resonance in higher education circles. Since the core business of HEls is student learning, it seems logical that the concept learning culture would fit HEls. After decades and many attempts to find the real meaning of and define the learning culture of specifically a university, the initial enthusiasm was tempered. It was finally realised that the complexity of an $\mathrm{HEI}$ and the diversity of staff and students, as well as the different nature of the practices, teaching and learning needs of the various disciplines, made it impossible to have a uniformly accepted learning culture at university level (Silver 2003). Although a university wide learning culture is not viable, the idea of a learning culture has merit. Knight and Trowler (2000) propose that at departmental level a uniform learning culture could be beneficial, but warned that even at this level there is still too much diversity to easily find a general departmental culture.

This implies that even at departmental level the concept learning culture should be interpreted only in terms of departmental practices related to student learning. It will thus have to be narrowed down to specific practices that represent a negotiated set of values (what is important), beliefs (what can work and how should it work) and norms (what behaviour is encouraged and rewarded) in relation to teaching, learning and assessment in the department. Since it is difficult to separate what lecturers do in their classes from who they are, it is necessary to find departmental values, beliefs and norms related to generic teaching, learning and assessment methods. In this way it will not stifle lecturers' autonomy (CHE 2013) and creativity but leave them scope to decide how the departmental learning culture manifests in their classroom practices.

To further explain what is meant by a department's values, beliefs and norms regarding learning, one can compare two departments that both value quality education but with different approaches to education, namely a student-centred and a teacher-centred approach respectively. In the first department it will be considered to be important that students are actively involved (Exeter et al. 2010) in their own learning process that they will learn where and how to find information. These students will also have to learn how to interpret and critically assess the quality of the information and how to apply and transfer information to various situations (Candy 2000). This department will focus on the learning process and enable students to learn on their own and develop skills that will empower them to become lifelong learners. Teachers will be facilitators of learning (Maor 2003) and use both formative and summative assessment (Yorke 2011). Creativity, insight and the ability to apply basic principles in various settings (Candy 2000) will be encouraged and rewarded.

A department that values teacher-centred learning like lecturing will probably focus on the transfer of high quality course content. Such an institution will make sure that students receive a wide range of information from well qualified subject experts who will tell them how to interpret the information and coach them to apply this information. Students will have to study the information they receive and demonstrate their knowledge and progress by frequently sitting for tests. Summative assessment will thus be used to determine to what extent students have mastered the subject content (Ellery 2008). Hard work and the ability to remember and reproduce large volumes of information (Mayer 2002) will be rewarded.

Each of these departments has a different learning culture because their values, beliefs and norms related to teaching, learning and assessment, differ. Both will draw a variety of students of whom some will achieve excellent and some poor results. However, the learning outcomes will be different, because the definition of quality education and thus the educational goals of the two departments are different. Both these approaches are necessary in the large class context, therefore it is suggested that the departmental learning culture should foster the use of a variety of teaching, learning and assessment methods in large classes so that a diversity of students will be enabled to learn and to develop. Gibbs et al. (2008) suggest that the academic department of research intensive universities is the appropriate place to effect change. This can be achieved by building a 'community of practice' (Wenger 1998) that involves the whole department, fosters discussion and debate about teaching and learning and where innovative teaching and assessment practices are recognised and rewarded.

\subsection{Formative assessment in large classes}

Both the student-centred and teacher-centred approaches have a place in the large classroom. In spite of in-depth research into alternative teaching, learning and assessment methods (Exeter et al. 2010) that can be used in the large classes to enable a student-centred approach, the logistically complex setting results in limited use of these methods in large classes (Mulryan-Kyne 2010). Apart from the logistical challenges, both lecturer and student attitudes can hamper the implementation of student-centred classroom practices. It is therefore proposed by the authors that the departmental 
learning culture should foster these practices and it is suggested that student-centred formative assessment is a viable practice in a large class context and thus a good place to start. Our use of student-centred formative assessment refers to peer- and self-assessment that is structured by the lecturer but not marked by the lecturer. It is used for learning and development purposes, not for grade allocation. The rationale for this proposition is explained in the following section.

\subsection{Student-centred formative assessment}

Although formative assessment and feedback can assist students to succeed, lecturers of large classes with diverse students tend to focus more on summative assessment (Yorke 2011). This limits the function of assessment to the allocation of marks rather than being an essential part of student learning. The emphasis on marks and grading can lead to the misconception that formative assessment means frequent testing that must be marked by lecturers and that must include thorough feedback from the lecturer. This view of formative assessment excludes the possibility of making use of peer- and self-assessment in large classes, because marks allocated by students are not always reliable. Contrasting results were yielded by studies that compared marks allocated by academic staff and by students. For example, Kirby and Downs (2007) in their study of under-prepared South African students found up to 20\% differences between the mean of some of the self-assessment marks of students and the mean of staff marking. Although they consider the development of students' self-assessment ability as a crucial component of the students' education, they warn against using self-assessment marks for grading purposes. Several authors (Andrade \& Valtcheva 2009) support the use of selfassessment for development purpose rather than grading. Lew et al. (2010) found that the self-assessment marks of students with higher grades are more aligned to lecturers' assessment than that of students with lower grades, but it is still an unreliable measure of student performance if all students' mark allocation cannot be used.

Despite the challenges it poses in large classes, developing students' self-assessment ability is necessary since it is essential for lifelong learning (Tamjid \& Birjandi 2011). Being able to assess their own work can give students a feeling of ownership of their learning and increase their awareness that they are responsible for their own learning. Students also need to be able to judge the quality of their own work throughout their professional careers (Donham 2010).

Reflection is at the core of self-assessment. Reflection on their work should thus become habitual and part of student practice in and outside the classroom (Herington \& Weaver 2008). Without reflection on assessment tasks, learning does not take place (Mezirow 1990). During self-reflection, and thus also during self-assessment, students must observe their work using specific criteria, they must analyse the work by closely inspecting different parts of it, they must judge its quality against the set criteria and they must plan how to improve it based on their own assessment of their current performance (Alverno College 2001 in Donham 2010).

Although a similar process is followed during peer assessment, but with someone else's work, students find peer assessment easier than self-assessment (Nicol 2007). Research into the quality of marks allocated by peers (Papinczak et al. 2007; Lew et al. 2010) indicates that peer marking on average is closer to staff marking than is the case with selfassessment. The use of peer-assessment can thus assist to develop the self-assessment skills of students.

The introduction of problem-based learning into the Health Sciences curriculum increased the use of peer assessment in health education, as well as research into the benefits and issues related to its use (Papinczak et al. 2007). The research is not limited to health education. One of the benefits that are relevant to large classes is that peer assessment is a social process and can assist to counter the feeling of isolation that many first year students experience in large classes (AUTC 2001 in Moulding 2010). However, Cartney (2010) warns that if peer assessment is used for grading, students can feel that they are treated unfairly and it can thus create feelings of anxiety or anger, which can jeopardise cognitive functioning. Ballantyne, Hughes and Mylonas (2002 in Lew et al. 2010) found that using their knowledge and skills to assess the quality of the work of peers enhances students' understanding of the work, their use of metacognitive skills and thus their understanding of their own learning process. In support of these authors, we emphasise that peer assessment should be used for the development of higher order thinking skills in large classes and not for grading purposes.

Nicol (2007) discusses the negative effects of large classes on assessment. These effects are reduced opportunities for students to clarify what is expected of them, a reduction in feedback on assignments and an increased emphasis on summative assessment at the expense of formative assessment. He further emphasises that students need to be aware of what academic success entails already in their first year of study and considers formative assessment and feedback as a way to create this awareness. We found similar effects in our study, which was conducted as follows. 


\section{Research Methodology}

A mixed method approach was used to simultaneously collect qualitative data by interviewing 14 lecturers and quantitative data by means of a survey of 2988 students about their experiences in a large class context. Only the qualitative results of the study are presented in this article.

\subsection{Data collection}

The two groups of people targeted for this study were lecturers and students in the faculty of Economic and Financial Sciences. This faculty at the specific South African university has the largest number of registered students. Therefore this faculty was selected for investigation of the experiences and challenges faced in large classes. The figures for 2010 (HEDA 2010) were 76257 of which 71562 were undergraduate and 4695 postgraduate. Only undergraduate students and their lecturers were included in the study.

The inclusion criteria for lecturers were that they must be full-time staff members and must teach at least one large undergraduate class (over 150 students per class) during 2011. Fourteen ( 3 male and 11 female) of the 20 lecturers that were approached took part in the study. The number of students taught in their largest class ranged between 180 and 800 students. The academic subjects taught in these classes were marketing, finance, accountancy, business management, information systems and economics. Their lecturing experience ranged from 6 months to 27 years. The mean length of time at the specific university was 7 years.

In-depth interviews, which lasted about 40 minute on average, were conducted with these lecturers to identify what challenges they encounter with teaching and assessment of large classes, as well as to obtain suggestions of ways in which the University could assist in overcoming these challenges. The interview guide of questions is presented in Table 1.

Table 1: Lecturers' experiences of large classes: Interview guide

1. How do you manage your large classes?

2. What methods do you use in your large classes?

3. What is your opinion of the tutorial system?

4. How do you assess students in large classes?

5. Please share with me any innovative strategies that you use to cope with the large classes.

6. What suggestions do you have for support from the university in terms of large classes?

The purpose of the study was explained to the lecturers and permission to conduct the study was granted by the relevant institutional authorities. Participation was voluntary and both anonymity and confidentiality were assured.

\subsection{Data analysis}

The qualitative data analysis of the transcriptions of the in-depth interviews was done with the use of ATLAS.ti software. Qualitative content analysis according to the steps suggested by Henning et al. (2004) was the method of analysis. These steps imply an inductive approach involving fine coding, categorisation of codes and identification of themes.

\section{Findings}

The findings that are presented relate to current practice in large classes, hindrances to student-centred learning and lecturers' willingness to learn and adapt to new classroom practices. The reference system $P 1, P 2$ to $P_{n}$ that is used with verbatim quotes indicates which participant is the source of the quotation. The Afrikaans quotations were translated and indicated by adding a ' $\mathrm{t}$ ' to the identification, for example P3t.

\subsection{Current practice}

It was found that although different methods are used in large classes, lecturers often struggle due to the large number of students and revert to traditional approaches to teaching and learning. They often used lectures with power point slides. 
This in itself is not a problem, as long as it is not the only method used in class. The following comments by participants illustrate their classroom practice.

There is just an absolute transfer of knowledge. There isn't even time to answer questions. (P14)

But the majority, I would say $80 \%$, consists of power point slides. (P11t)

Some of the young lecturers tried to cover the whole text book in class as indicated by the remark "in the beginning I converted almost the whole text book into slides (P6t)", while others out of compassion with the students provided too much assistance, thereby depriving the students of the opportunity to develop as independent learners.

With the students we have in front of us, it feels as if they are less capable to function independently. You cannot tell them 'I am just going to do these three things and the rest is self study'. It makes them very nervous - you must do all the work with them. (P2t)

This remark indicates the need for a paradigm shift for both the lecturer and students. Students need to realise that successful study at a higher education has different requirements than that of the school and that their success is mainly their own responsibility. The best time to let them realise this is at first year level. Some lecturers are aware of this and commented:

\begin{abstract}
Although they work very hard, they're not using the right strategies. They think that by working hard they can learn the entire textbook, while I want their opinion, justification and reasons, and they're not used to that. (P8)

And I think tapping into the first years, because that's where we can make or break the students ... Being in this kind of situation ... where you're really developing young minds, where you're encouraging people to think critically ... I think one of the problems with South Africa is that we were always taught what to think, not how to think. (P7)
\end{abstract}

There are lecturers who realise the importance of gradually developing the students' independence and thus scaffold tasks in class "... it is not spoon-feeding ... rather that you break down things so that they can see better" (P6t). Others realise that there has to be interaction and assistance in class to understand the work, not merely a repetition of textbook content.

You need to make learning easier for them otherwise they could just as well stay at home and self-study the work. Also, you must get the students' opinions on things, and make sure they follow all the examples, even give them time to make their own examples, to make sure they are following the work. (P10)

But many find engaging students in the large class difficult and are concerned about the effect of feelings of isolation in the class on first year students.

...so you can't engage with them.... what made it most difficult for me was the engagement or the lack of it. And the fact that the students get bored and they lose interest, and it doesn't take long for them to lose interest and start playing on their cell phones and then you've lost them. (P1)

With such a large group you cannot really evoke interaction ... that is a very important aspect of education that gets lost. (P9t)

In a larger group they are also not prepared to communicate with you, and they are scared to answer you. (P5t)

Sometimes they feel in a large class they are just a number and that you do not notice them. (P11t)

Interaction and engaging students in class are not the only challenge faced by lecturers in the large class context.

\title{
4.2 Hindrances to incorporate student-centred methods
}

Lecturers find using a variety of teaching and assessment methods difficult in a large class especially those that involve group work.

But then again, how practical is it for a large group of 800 , to give them some other assessment like field work or... you know, for them to give that kind of feedback, it's going to be difficult ... these ones here, can't do assignments. They are now at ... an unfair disadvantage, because of the class size. (P1)

They say we must get more participation, but they do not say how. They say we must do more group work, but they do not say how. $(P 2 t)$ 
Monitoring student progress also poses a huge challenge.

....we don't know about problems until we hit tests ... I mean you ask, do you understand, and then they'll say yes, because it's five minutes before the end of the lecture. So that's the problem. You do not really know if they understand till you get to a test. (P4)

Electronic tests by means of MCQs may be appropriate for assessing content knowledge but lecturers battle with developing and assessing higher level cognitive functioning in the large class as illustrated by the following comment.

\begin{abstract}
I think first and second year level is that [MCQ]. But when you start moving further on, you need to understand why... and then you need that dialogue and discussion in the class. And that with 700 students must be totally almost impossible to do. (P4)

It is still first and second level - I'm talking about Bloom's taxonomy... Then they get to my course, and l'm trying to get them to that level three, four and five. They struggle with that, obviously because they haven't been exposed to it in their first and second year. (P8)

Often a student can recite a situation or example of the concept from the textbook, but when you ask them to apply the same model to a different situation, there are problems. (P12)
\end{abstract}

Some lecturers realise the importance of developing higher level thinking skills and try to overcome the difficulties inherent in large classes.

\begin{abstract}
Students must still learn the same skills and do the same activities whether they are in bigger or smaller classes. (P11t) We have done multiple choice for 2 years... we have moved away from this. Next year they are going to write again, because we find our students in our second year can't write anymore. (P14t)
\end{abstract}

Conversations with colleagues sometimes are helpful, but in other cases colleagues cause additional challenges.

\begin{abstract}
So we have media sessions where we talk about teaching and learning specifically... and what has this one done, and how does this work, so we have it in subjects ..., but also within our department. So if we do that often, it will be nice to learn from others. ( $P$ 4)

I find one of the challenges is communication among all lecturers. If something is encountered in a class to communicate it to other lecturers, so that we all can address the same problems. (P11t)

Last year I used to do class tests as well, so the admin load for that is very heavy ... I had a discussion with my colleagues ... and I actually received a lot of criticism from them because I was employing time consuming methods and I wasn't concentrating on my research ... The other lecturers who have large groups, they're not very receptive, because they just want to stick to the old structure, they just want to get the lecturing done. (P8)
\end{abstract}

These kinds of challenges would be addressed by a departmental learning culture that values the use of a variety of methods in large classes and have norms about what is appropriate and rewarded in large classes. The viability of a negotiated departmental learning culture is indicated by many of the participants' willingness to learn about different methods.

\title{
4.3 Willingness of lecturers to learn and adapt
}

Several lecturers indicated that they would welcome training related to teaching, learning and assessment methods and mentioned the following learning needs.

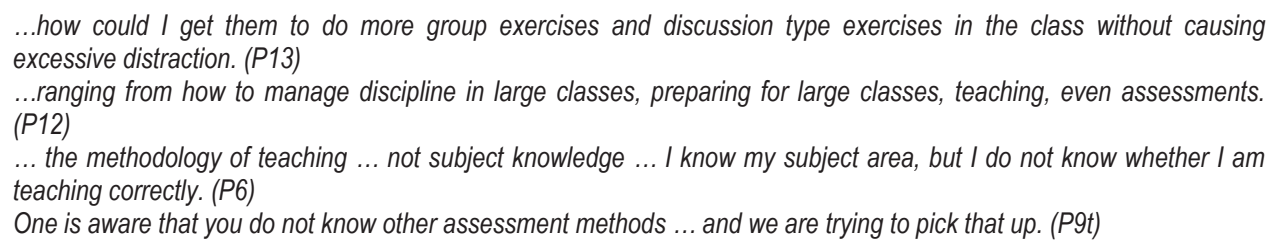

The success of using a variety of methods in large classes is not only dependent on the lecturers' ability and willingness to learn and adapt, but also on the extent to which there is buy-in from all staff members in the department to support and apply both teacher- and student-centred classroom practices. 


\section{Discussion}

Our findings related to current practice, namely that lectures are used to transfer knowledge and MCQs for assessment, are similar to the international trend to follow a teacher-centred approach in large classes is reported by Shavelson (2007). The logistical difficulties to implement student-centred methods like group work and the challenges related to assessment and feedback in large classes confirm Nicol's (2007) findings. Change is only possible if lecturers are prepared to implement new strategies. Although there were clear indications in our study of lecturers' willingness to change their current practice, they were not prepared to do that unconditionally. Apart from their need for knowledge about alternatives, of which some are suggested by amongst others, Gibbs (1992), they also need practical ways to implement the suggested strategies in the SA large class context. The resistance of colleagues towards individual lecturers, who tried out new methods, reinforces the suggestion by Gibbs et al. (2008) that change should take place at departmental level. This is also why we suggest that the departmental learning culture should promote the inclusion of student-centred strategies in large classes. Apart from the resistance by colleagues, we also found that there is student resistance to the use of alternative methods if only a few lecturers use these methods.

A departmental learning culture can create a community of practice whose members' personal and intellectual investments are valued (Wenger 1998). This kind of departmental environment does not only enable lecturers to share innovative ideas and successful practices, but can also make the student-centred methods part of the accepted methods used in large classes. First year students, being new to the higher education environment, will accept and adapt to whatever they experience as standard classroom practice. A departmental learning culture that fosters student-centred methods will thus prevent a situation where efforts by individual lecturers to engage students are met with resistance because of other lecturers' traditional practices.

Because of the logistical complexity of using some of the student-centred methods in a large class, we propose the incorporation of formative assessment in first year classes. Self- and peer assessment that build on students' existing skills can be a viable strategy to develop students' higher order thinking skills. The reasons why we suggest the implementation of this strategy even in extremely large and diverse classes are as follows. Although they are not always consciously aware of it, students constantly use reflection, which is at the core of self-assessment (Donham 2010). For example, in a lecture students need to reflect on what is said by the lecturer in order to internalise the information. When they are not rote learning, students reflect on the written text in the learning material in order to understand it. In their communication with peers they reflect on the verbal contents of the conversation in order to decide whether they agree with it or not. This means that they are constantly using reflection to assess what others say and do, but they do not reflect on their own work to assess its quality, and therefore they do not derive the intended value in terms of learning from their assignments. We need to turn this already existing natural practice of reflection into habitual practice in the learning environment. As Nicol (2007) mentions, being able to assess their own work against criteria set by the lecturer, can assist students to set realistic goals and allow them to realise how much effort is necessary to achieve their learning goals.

As suggested by several authors (Papinczak et al. 2007; Lew et al. 2010) peer assessment can assist in developing students' self-assessment skills. There are several opportunities in large classes to use peer- and selfassessment. For example, the lecturer can give time during class for individual reflection on a section of the work that was just taught and require students to write a paragraph about it - similar to the 'one-minute paper' proposed by Cross and Angelo (1993). The follow-up of the minute paper can vary. It can be followed by either discussing each student's understanding with the peer next to the student, a form of buzz group (Cantillon 2003), followed by questions to the lecturer to clarify differences. Alternatively, the lecturer can provide criteria to mark against and require students to mark their own paper (self-assessment) or hand it to the student sitting next to or in front or behind the student to be marked (peer assessment). The instructions to students and criteria provided for marking during subsequent classes can be scaffolded to require higher order thinking as follows:

- Students initially are requested to just give a summary of main points of the lecture.

- Then they must explain their understanding of a specific aspect that was discussed during the class

- Later they must provide the main argument plus two or three pieces of evidence for the argument

- This can be followed by the lecturer providing a paragraph about the work that students need to critique.

Any of these alternatives increases student engagement. If all lecturers in a department use this kind of peer- and self-assessment in their large first year classes, it will become part of classroom practice in that department and students will not be resistant to take part in the activities. 


\section{Conclusion}

The current focus in South Africa is on open access and throughput rates, forces lecturers to produce evidence that students have mastered the course content. Open access often results in unmanageable large classes and the struggle to cover content in this context leaves lecturers with very few other options than to revert to lecturing. Our findings indicate that lecturers of large classes still predominantly use lecturing and MCQs for assessment, but they are willing change. The critical cross-field outcomes that were designed to promote self-directed lifelong learners cannot be achieved by lecturing and summative assessment in the form of electronic MCQs only. Unless lecturers of large classes are supported with training to use alternative methods, our institutions will produce graduates who never had the opportunity to develop the lifelong learning skills that they will need to survive in the workplace.

We propose that the way to start changing this situation is by using peer and self-assessment in large classes, and suggest some practical guidelines for implementing these formative assessment methods even in very large and diverse classes. More research is necessary to identify the challenges related to using peer and self-assessment as standard classroom practice in a department with large classes, because unless all lecturers apply these methods in their classes it will not be successful. It is therefore necessary to cultivate a departmental learning culture that values both teacher- and student-centred methods, that believes students need to learn more than just subject content, and where the norm is to assess and reward both indicators of higher order thinking ability as well as mastery of crucial factual knowledge of the discipline.

\section{References}

Andrade, H., \& Valtcheva, A. (2009). Promoting learning and achievement through self-assessment. Theory into Practice, 48, 12-19.

Biggs, J. (1999). What the student does: Teaching for enhanced learning. Higher Education Research and Development, 18(1), 57-75.

Candy, P.C. (1991). Self-direction for lifelong learning: A comprehensive guide to theory and practice. Oxford (UK): Jossey-Bass.

Candy, P.C. (2000). Knowledge navigators and lifelong learners: Producing graduates for the information society. Higher Education Research and Development, 19(3), 261-277.

Cantillon, P. (2003). Teaching large groups. British Medical Journal, 326(7386), 437-441.

Cheng, M. (2012). Accountability and professionalism: A contradiction in terms? Higher Education Research and Development, 31(6), 785-795.

Conner, T.W., \& Rabovsky, T.M. (2011). Accountability, affordability, access: A review of the recent trends in higher education policy research. Policy Studies Journal, 39(S1), 93-112.

Cartney, P. (2010). Exploring the use of peer assessment as a vehicle for closing the gap between feedback given and feedback used. Assessment and Evaluation in Higher Education, 35(5), 551-564.

CHE (Council on Higher Education of South Africa) (2008). Academic freedom, institutional autonomy and public accountability in South African Higher Education (Pretoria, Council on Higher Education). [Online] Available: http://www.che.ac.za/documents/d000183/CHEHEIAAF_Report_Aug2008.pdf (February 28, 2013).

CHE (Council on Higher Education) (2013). A framework for qualification standards in Higher Education. Second draft. Pretoria: Council on Higher Education. [Online] Available: http://www.che.ac.za/documents/d000248/second_draft_framework_for_qualification _standards_in_higher_education_january_2013.pdf (February 28, 2013).

Cross, K.P., \& Angèlo, T.A. (1993). Classroom assessment techniques. A handbook for college teachers. San Francisco, CA: Jossey-Bass.

De Zilwa, D. (2007). Organisational culture and values and the adaptation of academic units in Australian Universities. Higher Education, $54,557-574$.

DHET (Department of Higher Education and Training) (2007). The Higher education Qualifications Framework. Government Gazette No.30353 Oct 2007. [Online] Available: http://www.dhet.gov.za/portals/O/Documents/Higher_Education_Qualifications Framework_Oct2007.pdf (February 20, 2013).

DoE (Department of Education) (1997). Education White Paper 3: A programme for the transformation of higher education. Pretoria: Department of Education.

DoE (Department of Education) (2001). Draft National Academic Plan in South Africa. Pretoria: Government Printers.

Donham, J. (2010). Creating personal learning through self assessment. Teacher Librarian, 37(3), 14-21.

Elen, J., Clarebout, G., Le'onard, R., \& Lowyck, J. (2007). Student-centred and teacher-centred learning environments: What students think. Teaching in Higher Education, 12(1), 105-117.

Ellery, K. (2008). Assessment for learning: A case study using feedback effectively in an essay-style test. Assessment and Evaluation in Higher Education, 33(4), 421-429.

Exeter, D.J., Ameratunga, S., Ratima, M., Morton, S., Dickson, M., Hsu, D., \& Jackson, R. (2010). Student engagement in very large classes: The teachers' perspective. Studies in Higher Education, 35(7), 761-775.

Gibbs, G. (1992). Improving the quality of student learning. Bristol (UK): Technical and Educational Services.

Gibbs, G., Knapper, C., \& Piccinin, S. (2008). Contextually appropriate approahes to leadership of teaching in research-intensive academc departments in higher education. Higher Education Quaterly, 62(4), 416-436. 
Guzman, G., \& Trivelato, L.F. (2011). Packaging and unpackaging knowledge in mass higher education: A knowledge management perspective. Higher Education, 62, 451-465.

HEDA (Higher Education Data Analyser) (2010). Unpublished student tracking system of the University of Johannesburg, South Africa. Johannesburg: University of Johannesburg.

Henning, E., Van Rensburg, W., \& Smit, B. (2004). Finding your way in qualitative research. Pretoria: Van Schaik.

Herington, W., \& Weaver, S. (2008). Action research and reflection on student approaches to learning in large first year university classes. Australian Educational Researcher, 35(3), 111-134.

Holyoke, L.B., Sturko, P.A., Wood, N., \& Wu, L.J. (2012). Are academic departments perceived as learning organizations? Educational Management, Administration and Leadership, 40(4), 436-448.

Jones, A. (2009). Generic attributes as espoused theory: The importance of context. Higher Education, 58, 175-191.

Kirby, N.F., \& Downs, C.T. (2007). Self-assessment and the disadvantaged student: Potential for encouraging self-regulated learning? Assessment and Evaluation in Higher Education, 32(4), 475-494.

Knight, P.T., \& Trowler, P.R. (2000). Department-level cultures and the improvement of learning and teaching. Studies in Higher Education, 25(1), 69-83.

Lew, M.L.D.N., Alwis, W., \& Schmidt, H.G. (2010). Accuracy of students' self-assessement and their beliefs about its utility. Assessment and Evaluation in Higher Education, 35(2), 135-156.

Liu, O.L. (2011). Outcomes assessment in higher education: Challenges and future research in the context of voluntary system of accountability. Educational Measurement: Issues and Practice, 30(3), 2-9.

Maor, D. (2003). The teacher's role in developing interaction and reflection in an online learning community. Education Media International, 40(1/2), 127-137.

Mayer, R.E. (2002). Rote versus meaningful learning. Theory into Practice, 41(4), 226-232.

McKeachie, W. (1999). Teaching tips. Boston, MA: Houghton Mifflin.

Metz, T. (2010). A dilemma regarding academic freedom and public accountability in higher education. Journal of Philosophy of Education, 44(4), 528-549.

Mezirow, J. (1990). Fostering critical reflection in adulthood: A guide to transformative and emancipatory learning. San Francisco, CA: Jossey-Bass.

Mompo, R., \& Redoli, J. (2010). Some Internet-based strategies that help solve the problem of teaching large groups of engineering students. Innovations in Education and Teaching International, 47(1), 95-102.

Moulding, N.T. (2010). Intelligent design: Student perceptions of teaching and learning in large social work classes. Higher Education Research and Development, 29(2), 151-165.

Mulryan-Kyne, C. (2010). Teaching large classes at college and university level: Challenges and opportunities. Teaching in Higher Education, 5(2), 175-185.

Naidoo, K., \& Searle, R. (1997). Alternative teaching strategies. New directions for teaching and learning, 72, 11-21.

Nicol, D. (2007). Laying a foundation for lifelong learning: Case studies of e-assessment in large 1st-year classes. British Journal of Educational Technology, 38(4), 668-678.

Nicol D.J., \& Boyle, J.T. (2003). Peer instruction versus class-wide discussion in large classes: A comparison of two interaction methods in the wired classroom. Studies in Higher Education, 28(4), 457-473.

Papinczak, T., Young, L., Groves, M., \& Haynes, M. (2007). An analysis of peer, self and tutor assessment in problem-based learning tutorials. Medical Teacher, 29, 122-132.

Papo, W. (2001). Integration of educational media in higher education large classes. Education Media International, 38(2/3), 95-99.

Paxton, M. (2000). A linguistic perspective on multiple choice questioning. Assessment and Evaluation in Higher Education, 25(2), 109119.

Robbins, S.P. (1996). Organizational behavior (7th ed.). Englewood Cliffs, NJ: Prentice Hall

Schapper, J.M., \& Mayson, S.E. (2004). Internationalisation of curricula: An alternative to the taylorisation of academic work. Journal of Higher Education Policy and Management, 26(2), 189-205.

Senge, P.M. (1990). The fifth discipline: The art and craft of the learning organization. New York: Random House.

Shavelson, R.J. (2007). Assessing student learning responsibly: From history to audacious proposal. Change, 39(1), 26-33.

Silver, H. (2003). Does a university have a culture? Studies in Higher Education, 28(2), 157-169.

Switzer, J.S. (2004). Teaching computer-mediated visual communication to a large section: A constructivist approach. Innovative Higher Education, 29(2), 89-101.

Tamjid, N.H., \& Birjandi, P. (2011). Fostering learner autonomy through peer- and self-assessment. International Journal of Academic Research, 3(5), 245-251.

Van den Berg, P.T., \& Wilderom, P.M.C. (2004). Defining, measuring and comparing organisational cultures. Applied Psychology: An international review, 53(4), 570-582.

Wenger, E. (1998). Communities of practice: Learning, meaning and identity. Cambridge (UK): University Press.

Yorke, M. (2011). Summative assessment: Dealing with the "measurement fallacy". Studies in Higher Education, 36(3), $251-273$.

Yuen, K-M., \& Hau, K-T. (2006). Constructivist teaching and teacher-centred teaching: A comparison of students' learning in a university course. Innovations in Education and Teaching International, 43(3), 279-290. 